\title{
Corrigendum
}

\section{Candidate Genes Expression Profile Associated with Antidepressants Response in the GENDEP Study: Differentiating between Baseline 'Predictors' and Longitudinal 'Targets'}

\begin{abstract}
Annamaria Cattaneo, Massimo Gennarelli, Rudolf Uher, Gerome Breen, Anne Farmer, Katherine J Aitchison, lan W Craig, Christoph Anacker, Patricia A Zunsztain, Peter McGuffin and Carmine M Pariante
\end{abstract}

Neuropsychopharmacology (2013) 38, 376; doi: I0.1038/npp.20 I2.2I I

Correction to: Neuropsychopharmacology advance online publication, 19 September 2012; doi:10.1038/npp.2012.191
In this article, the name of the ninth author is incorrect. The correct name is Patricia A Zunszain. 